\title{
Paid, Owned and Earned Media: A Qualitative Comparative Analysis revealing Attributes Influencing Consumer's Brand Attitude in Social Media
}

\author{
Jens Mattke \\ University of Bamberg \\ jens.mattke@uni-bamberg.de
}

\author{
Lea Müller \\ University of Bamberg \\ lea.mueller@uni-bamberg.de
}

\author{
Christian Maier \\ University of Bamberg \\ christian.maier@uni-bamberg.de
}

\begin{abstract}
This paper examines how companies can use paid media (referring to sponsored posts), owned media (company posts) and earned media (influencer post) to create a positive brand attitude. Based on the advertising value model, this paper takes a configurational approach and uses fuzzy set qualitative comparative analysis ( $\left.f_{s} Q C A\right)$. The analysis reveals a typology of five types of media, which influence consumers' brand attitude positively. We contribute to research by providing a typology of paid, owned and earned media, which can guide companies to create a positive brand attitude.
\end{abstract}

\section{Introduction}

Companies, such as Nike, use social media to build a strong brand, indicated by consumers' brand attitude. It is known that brand attitude is the main driver for increased profits. For instance, a positive brand attitude leads to consumers' commitment to the company and influences consumers to buy products of the company instead of choosing a similar product of a competitor [2, 52, 53]. Companies using social media rely on three different media types to advertise on platforms like Instagram or Facebook with the objective to create a positive brand attitude [45]. In 2018, US companies will spend around \$24 billion on sponsored posts (paid media) [50], around \$2 billion on influencer marketing (earned media) [47] and will post their own content around eight times a day (owned media) via their social media fan pages [33]. Practically and theoretically, it is unclear, how consumers differently perceive these three types of media [3], and which attributes of each type contribute to build a positive brand attitude. However, it is important for companies to know, how the three types of media differ in influencing a consumer to develop a positive brand attitude. With this knowledge, companies could optimize their budget allocation for paid, owned and earned media to build a strong brand and to use the three types of media in the most appropriated context. To particularly fill this gap, we answer the following research question:

How do paid, owned and earned media influence consumers' brand attitude?

From a theoretical perspective the advertising value model (AVM) [12] provides a theoretical lens to explain consumers' response to the three types of media $[10,54]$. This means for our context that whenever a consumer is confronted with paid, owned or earned media, he evaluates different attributes of the media, such as the entertainment, informativeness and irritation, as well as the credibility of the media $[5,10]$ and the product involvement [20]. In summary, the five attributes determine consumers' assessment of the media and influence consumers' brand attitude [17]. We know that the relationship between the attributes, as in real live, is more likely to be asymmetric rather than symmetric [23, 40]. Following recommendations [23], we take a configurational approach using fuzzy set QCA (fsQCA), which allows the modelling of asymmetric relationships between attributes [30]. Therefore, we need to view consumers' brand attitude as a result of the interconnected attributes. This means that an attribute may affect consumers' brand attitude only given the presence or absence of one or more attributes, which is known as a configuration of sufficient attributes. Therefore, in this study, a configuration of sufficient attributes is defined as a specific set of attributes that leads to a positive brand attitude. The results reveal one configuration of sufficient attributes for paid media, two for owned media and two for earned media, which all lead to a positive brand attitude.

With this research we contribute to social media marketing research by examining five configurations of sufficient attributes, which all differ in their attributes but all lead to a positive brand attitude. Furthermore, we reveal different necessary attributes for paid, owned and earned media and thereby show that some attributes are more important and need to be present, so that a media evokes a positive brand attitude. With this, we build a typology of paid, owned 
and earned media, which guides companies to optimize their usage of paid, owned and earned media.

In Section 2 we will outline the research background. In Section 3 the methodology is described and in Section 4 we provide a summary of the results, which are discussed in Section 5.

\section{Theoretical Background}

In this section we will first discuss paid, owned and earned media, which companies can use in social media marketing to generate a positive brand attitude. We then explain the advertising value model (AVM), which is used as the theoretical lens to explain how the three types of media influence consumers' brand attitude.

\subsection{Paid, owned earned media}

Social media marketing has become a key pillar for companies to communicate to current and potential consumers [3]. Social media enables companies to directly promote their brand and products to consumers and get direct feedback. For this, companies use paid media, owned media and earned media in social media to generate a positive brand attitude [24, 45].

First, companies can use paid media to reach consumers and generate a positive brand attitude. Paid media refers to sponsored posts related to a brand, which are generated and payed by the respective company [45]. This means that companies create paid media and get charged by the social media platform, such as Instagram, for displaying the paid media to consumers in the newsfeed of the social media platform. Consumers are exposed to paid media, which are often labeled as 'sponsored posts' or 'promoted post'. Research on paid media in the context of social media has studied consumers' attitude towards paid media [46] and consumers' intention to click on paid media [53]. Recent studies found that clicks on paid media depend on consumers' assessment of the privacy policy of the social media platform [49] and that consumers' purchase intention in response to paid media is mainly driven by informativeness, entertainment and credibility of the paid media [10, 53], while consumers often avoid paid media, which hinders their browsing [28, 29].

Second, companies can leverage owned media to reach consumers and to evoke a positive brand attitude. Owned media refers to posts in social media, related to a brand, which is generated by the company and posted in the social media channel the company controls [24, 45]. This means that all posts, which are generated by a company and which are free of charge, refer to owned media. Owned media is displayed in the newsfeed of a consumer if she 'follows' the company via the social media platform. Little research has been done in the field of owned media in the context of social media [3]. Some research indicates that consumers' brand attitude and loyalty is influenced by owned media [55] and owned media was found to influence consumers' purchase behavior [52].

Third, an emergent trend for companies is to use earned media to influence consumers' brand attitude. Earned media refers to brand-related posts in social media which are not directly generated by the company but rather by an influencer. An influencer is a person with a sizable network of followers in social media [51]. This means that if an influencer shares selfgenerated content, such as pictures or videos related to the brand in their own newsfeed, all social media followers of the influencer see the post. Research found that earned media can outperform classical paid media, because earned media is sometimes perceived as more credible and trustworthy than paid media [21]. The influencer plays an important role and is often perceived as especially credible [51]. Consequently, earned media are often strongly associated with the influencer [31], but research found that consumers' brand attitude is positively influenced [48].

In summary, companies can use paid, owned and earned media in the context of social media to generate a positive brand attitude. Yet, so fare literature does not provide an overview, how consumers differently perceive these types of media and how companies need to differently manage those types to evoke a positive brand attitude [3]. Therefore, we take the AVM as a theoretical lens, which is outlined next.

\subsection{The Advertising Value Model (AVM)}

To understand how companies can differently use paid, owned and earned media to influence consumers' brand attitude, we base on the foundation of the AVM [12]. The AVM has been used to explain consumers' assessment of advertising in general and is widely used to explain consumers' assessment of online advertising, such as email advertising targeted online advertising and SMS advertising [8, 12]. Furthermore, it has been used for social media advertising [10], which attests the applicability of the AVM to examine and compare consumers' response to paid, owned and earned media.

The AVM states that different attributes of media forms the perceived value of the media, which is known to influence consumers' brand attitude [25]. The AVM identifies entertainment, informativeness and the irritation as relevant attributes of media [12]. Later, research extended the AVM and found that consumers additionally evaluate the credibility of the media [5, 10, 25] and the product involvement [37, 38] to assess media. This means that previous research indicates that those five attributes, which are outlined hereafter, shape consumers' brand attitude for paid, owned and earned media. In this study, brand attitude is defined as a learned predisposition to respond in a 
consistently favorable or unfavorable manner toward the brand [25]. A positive brand attitude is important for a company as it increases the brand awareness and image and consequently, increases sales [52]. Based on the AVM we know that entertainment of the media is evaluated by consumers. In this study, entertainment is defined as the ability of paid, owned or earned media to promote enjoyment or excitement $[12,20]$. Previous research has found that entertainment has a positive influence on consumers' evaluation of the media [12, 54] and consequently leads to a positive brand attitude [25]. Furthermore, informativeness of the media is evaluated by the consumers and refers to the attribute that paid, owned or earned media informs the consumer about the product and provides the consumer with necessary information to evaluate the product [12]. Previous research has examined that informativeness positively influences consumers' evaluation of the media [54] and therefore leads to a positive brand attitude [25]. The AVM furthermore states that irritation influences individuals' assessment of media. Based on previous research [12], we define irritation of paid, owned and earned media as consumers' perception to which paid, owned and earned media is causing displeasure and momentary impatience. Again, previous research repeatedly proved that irritation leads to a negative evaluation of paid media [12, 54] which previous research reveals in turn negatively influences brand attitude [25]. We furthermore know that credibility of paid, owned and earned media is an important attribute, which determines consumers' evaluation of the media and influences consumers' brand attitude [5, 10, 25]. Credibility refers to the perception of a consumer that the paid, owned or earned media is being honest and truthful [25]. Research has found that credibility leads to a positive assessment of the media [10, 22], which in turn leads to a positive brand attitude [25]. Finally, one of the most important attributes, which determines consumers' response to paid, owned and earned media is product involvement, which is defined as perceived personal importance and interest in the advertised product [37, 38]. Product involvement has been found to determine consumers' assessment of media and high product involvement has been found to lead to a positive brand attitude [20, 25].

So far, a lack of knowledge exists what role the attributes play and how the attributes of paid, owned and earned media influences consumers' brand attitude. Furthermore, recent research does not consider asymmetric relationships between those attributes. However a growing literature highlights [23, $30,40]$, that an attribute may affect consumers' brand attitude only given the presence or absence, of one or more attributes. For instance, informativeness of a media may only lead to a positive attitude towards a brand if the media is simultaneously perceived as credible. On the other hand, media that is not perceived as informative may still evoke a positive brand attitude, if the media is perceived as entertaining and not irritating. In other words, previous research has not considered that an attribute may only have an influence on brand attitude in combination with other attributes (known as conjunction), that the presence as well as the absence of attributes may be connected to brand attitude (known as asymmetric relationship) and that not one but multiple ways exist how a media can evoke a positive brand attitude (known as equifinality). To particularly address this this study conducts an online survey and takes a configurational approach using fuzzy set qualitative comparative analysis (fsQCA) [30] to reveal what configurations of sufficient attributes lead to a positive brand attitude.

\section{Research Methodology}

We, next outline the data collection approach, the used measures and the validation of the measurement model followed by the description of the data analysis with fsQCA.

Data Collection. To gather data, we conducted an online survey at a large university and used the snowball system to gather enough participants. Overall 177 participants filled out the survey, yet we removed 33 participants as they did not complete the survey. The final sample consists of 144 participants, which satisfies the sample size requirements of fsQCA [26]. The demographics are shown in Table 1 . When the participants entered the survey, they could choose between two products to avoid a product bias [4]. Participants were randomly assigned to one of three groups. The first group was assigned to paid media, meaning that they were exposed to a paid media mockup of the product they chose. The second group was exposed to owned media mockup presenting the product of choice and the last group was exposed to an earned media mockup about the product. We used mockups of Instagram because Instagram is common for paid, owned and earned media and has been used in social media studies before [7, 31]. We used fictional brands, which is commonly used in brand attitude studies [36], to avoid an already existing brand attitude. After the participants were exposed to either paid, owned or earned media, they filled out the rest of the survey. Following recommendations [9], we tested for common method bias. For this we applied the Harman's single factor test [39], which reveals the percentage of the variance explained by a single attribute. The test indicates that only 36.37 percent is explained by a single factor which is lower than the recommended upper limit of 50 percent. We additionally followed recommendation to examine the 
correlation matrix [35]. The correlation matrix does not reveal any high correlations (see Table 3), therefore we can state that common method bias is not an issue in this study.

Table 1. Demographics

\begin{tabular}{|l|l|l|l|}
\hline \multicolumn{2}{|l|}{ Age in percent } & \multicolumn{2}{l|}{ Gender in percent } \\
\hline $18-20$ & 4.20 & Male & 43.30 \\
\hline $21-30$ & 76.22 & Female & 56.70 \\
\hline $31-40$ & 8.39 & Time in social media \\
\hline $41-50$ & 3.50 & $<1$ hour & 53.40 \\
\hline $51-60$ & 7.69 & $1-2$ hour & 18.30 \\
\hline $\begin{array}{l}\text { Mean: } 28.60 \\
\text { Standard deviation: } 9.61\end{array}$ & $>1$ hour & 28.30 \\
\hline
\end{tabular}

Measures. We only used items used in previous research to ensure content validity. To measure consumers' brand attitude we based on six items previously used in IS research [17]. To measure entertainment, we used four items used in previous social media research [46]. We adapted seven items for informativeness and five items for irritation from previous research [12]. For credibility we based on previous research [5] and used three items. We used two items to measure consumers' product involvement [16]. A summary of the used items is shown in Table 2.

Table 2. Constructs

\begin{tabular}{|l}
\hline Attitude towards brand [17] \\
- $\quad$ Extremely unpleasant / pleasant $(0.915)$ \\
- $\quad$ Extremely unfavorable / favorable (0.909) \\
- $\quad$ Extremely dislike / like $(0.906)$ \\
- $\quad$ Extremely negative / positive $(0.029)$ \\
Entertainment [46] \\
- This media is fun to watch or read (0.88) \\
- This media is clever and quite entertaining \\
(0.912) \\
This media does not just sell - it also entertains \\
me (0.933) \\
Informativeness [12] \\
This media is a good source of product \\
information (0.815) \\
This media supplies relevant product \\
information (0.813) \\
- This media provides timely information (0.755) \\
This media is a good source of up-to-date \\
product information (0.807) \\
imis media makes product information \\
information (0.828) \\
\hline
\end{tabular}

- This media supplies complete product information (0.757)

\section{Irritation [12]}

- This media insults people's intelligence (0.778)

- $\quad$ This media is annoying (0.922)

- $\quad$ This media is irritating (0.922)

- $\quad$ This media is deceptive (0.839)

- This media is confusing (0.755)

Credibility [5]

- $\quad$ This media is credible (0.919)

- $\quad$ This media is trustworthy (0.953)

- $\quad$ This media is believable (0.934)

Product involvement [16]

- $\quad$ This product is very important to me (0.908)

- This product is an important part in my life (0.987)

Note: All items were measured with a 7-point Likert-type agreement scale ranging from 1 = "completely disagree" to 7 = "completely agree". Figures in brakes show the respective loadings of the item.

Measurement Model. We can state that indicator reliability is ensured, as all loadings are higher than 0.707 [6]. As indicated in Table 3, the average variance extracted (AVE) exceeds the recommended threshold of 0.50 , composite reliability (CR) exceeds the threshold of 0.70 and Cronbach's alpha exceeds the threshold of 0.70 for each construct, which attests construct reliability [15]. Discriminant validity is ensured as the square root of the AVE is higher than the corresponding correlation of the constructs (see Table 3) [15, 19]. We additionally calculated the heterotrait-monotrait (HTMT) ratio, which reveals 0.716 as the highest value. This is below the absolute criterion of 0.85 and therefore discriminant validity is attested [18].

Data analysis using fsQCA. To analyze which configurations of the five attributes, lead to a positive brand attitude for paid, owned and earned and thereby, to deal with the asymmetric relationship between the five attributes, we take a configurational approach. More precisely, we use fuzzy set qualitative comparative analysis (fsQCA), which enables us to understand the how the five attributes when acting together bring about a positive brand attitude. In other words, fsQCA enables us to understand configurations of the five attributes that bring about a positive brand attitude.

In summary, with this we depart from focusing on the net effect of single attributes [43] and focus on configuration of the five attributes that when working together lead to a positive brand attitude. We thereby can reveal whether the presence of absence of an attribute in combination with the other attributes is related to consumer's positive brand attitude. 


\begin{tabular}{|c|c|c|c|c|c|c|c|c|c|c|c|c|}
\hline \multicolumn{13}{|c|}{ Table 3. Measurement Model } \\
\hline & & Mean & SD & AVE & $\mathrm{CR}$ & $\alpha$ & 1 & 2 & 3 & 4 & 5 & 6 \\
\hline 1 & Entertainment & 3.09 & 1.54 & 0.81 & 0.95 & 0.92 & 0.90 & & & & & \\
\hline 2 & Informativeness & 3.65 & 1.29 & 0.63 & 0.92 & 0.90 & 0.54 & 0.79 & & & & \\
\hline 3 & Irritation & 3.77 & 1.51 & 0.72 & 0.93 & 0.90 & -0.47 & -0.48 & 0.85 & & & \\
\hline 4 & Product Involvement & 5.05 & 1.36 & 0.90 & 0.95 & 0.91 & -0.03 & 0.01 & 0.08 & 0.95 & & \\
\hline 5 & Credibility & 3.77 & 1.41 & 0.87 & 0.96 & 0.93 & 0.51 & 0.59 & -0.64 & -0.02 & 0.94 & \\
\hline 6 & Attitude Brand & 3.91 & 1.18 & 0.82 & 0.96 & 0.96 & 0.67 & 0.50 & -0.52 & -0.12 & 0.57 & 0.91 \\
\hline
\end{tabular}

Furthermore, fsQCA has been successfully used in online marketing and IS studies [27, 32, 34].

Data analysis. The data analysis with fsQCA consist of three steps: calibration of the survey data into fuzzy sets, the analysis of necessary attributes and the analysis of configurations of sufficient attributes, which when working together lead to a positive brand attitude. For all three steps we used the fsQCA software program [42]. To calibrate the data we followed recommendation [14, 30] and use the direct calibration for survey data. This means we calibrated the interval scale values of the five attributes $(1=$ "strongly disagree", $4=$ "neither agree in nor disagree", 7 = "strongly agree") into fuzzy sets, which range from 0 to 1 . For the calibration we used three recommended anchors (value 1 for full nonmembership; value 4 for the crossover point, value 7 for full membership). The calibration for fuzzy sets is needed as the base for the analysis of necessary attributes and the analysis of configurations of sufficient attributes.

Necessary attributes are attributes that need to be present if a media leads to a positive brand attitude. In other words, every time a consumer has a positive brand attitude, the necessary condition is present as well [43]. We tested for necessary attributes for paid media, owned media and earned media separately. As a result, we can say whether different necessary attributes exist for paid, owned and earned media. The analysis of necessary attributes requires that an attribute exceeds the consistency threshold of 0.90 [44], thus only attributes that have a higher consistency threshold are necessary attributes. In this study, the consistency indicates the degree to which cases with the same attribute show a positive brand attitude [43]. In summary this analysis reveals distinct necessary attributes for paid, owned and earned media, which are always present if a media leads to a positive brand attitude. Yet necessary attributes do not evoke a positive brand attitude, therefore we next analyze for configurations of sufficient attributes.

In this study, a configuration of sufficient attributes is a specific set of attributes that, when working together lead to a positive brand attitude [43]. This means every time the configuration of sufficient attributes is present the media will lead to positive brand attitude. We conducted the analysis for paid, owned and earned media separately. This enables us to study each type of media separately and to compare the different configurations of sufficient attributes leading to a positive attitude through paid, owned or earned media. To conduct this analysis, we first constructed the truth table. The truth table consist of all possible configurations of the five attributes. In this study we have five attributes therefore the truth table consist of $2^{\mathrm{k}}$ rows, with $\mathrm{k}$ being the number of attributes, thus 32 rows. Second, we follow recommendations [14, 44] and reduce the truth table to meaningful configurations. For this, we apply a frequency threshold of three, which means that only configurations with at least three observations are considered in the further analysis. We additionally applied a consistency threshold of 0.80 , meaning that only configurations with a consistency of at least 0.80 remain and are treated as sufficient. Consistency captures the extent to which a given configuration is a configuration of sufficient attributes for a positive brand attitude [23]. In other words, high consistency indicates that when the configuration occurs, that consumer will respond mandatorily with a positive brand attitude. Third, we applied the Quine-McCluskey algorithm to simplify the reduced truth table [43] and to reveal the final configuration of sufficient attributes, which lead to a positive brand attitude. In summary, this analysis reveals configurations of sufficient attributes for paid, owned and earned media, which lead to a positive brand attitude. 


\section{Results}

In this section, we first present the result for paid media then for owned media followed by the presentation of the results for earned media.

Results paid media. The analysis of necessary attributes revealed product involvement (consistency > 0.93 , coverage $>0.57$ ) to be a necessary attribute for consumer's positive brand attitude when the consumer is exposed to paid media.

This means that for paid media to evoke a positive brand attitude the advertised product needs to be relevant and important to the consumer. Yet, only the presence of product involvement does not lead to a positive brand attitude. To explain this the analysis of configuration of sufficient attributes reveals one configuration, which is graphical represented in Figure 1 (configuration C1). In Figure 1 we used black circles to indicate the presence of an attribute, e.g. a black circle for entertainment indicates that the consumer needs to perceive the paid media as entertaining. Crossed out white circles indicate the absence of an attribute, e.g. the crossed out white circle for irritation indicates that the consumer needs to perceive the paid media as non-irritating to that it leads to a positive brand attitude. Furthermore, we included the results of the necessary attributes in the graphical solution, by using stars to indicate necessary attributes. A filled out black star indicates the presence of an attribute being a necessary attribute and a white stare indicate the absence of an attribute and simultaneously being a necessary attribute. The overall solution consistency is 1.00 and the coverage is 0.52 . Coverage thereby is a measure of the proposition of cases explained by the configurations.

Configuration C1 states that for paid media to evoke a positive brand attitude the consumer needs to have product involvement, needs to perceive the media as entertaining, non-irritating, informative and credible. This configuration only contains the presents of positive influencing attributes and the absence of irritation as the negative influencing attribute, and therefore reflects an ideal paid media. We consequently label this configuration the ideal paid media.

Results for owned media. The analysis of necessary attributes for owned media did not reveal any necessary results. The analysis of configurations of sufficient attributes revealed two configurations (see Figure 1 configurations C2 and C3). We used blank spaces to indicate a "don't care" situation, meaning that the attribute can either be present or absent. The overall solution consistency is 0.86 and the coverage 0.67. Configuration C2 reveals that owned media, which is perceived as non-entertaining, non-irritating, but is perceived as informative and credible, leads to a positive brand attitude. In this configuration, product involvement plays a subordinated role as it can either be present or absent. This configuration reflects an owned media, for which it does not matter whether the product is relevant for the consumer yet leading to a positive brand attitude. We therefore label this configuration as the indifferent product owned media. Configuration C3 on the other hand shows that owned media can also lead to a positive brand attitude if the consumer perceives the product advertised in the owned media as relevant and important, thus high

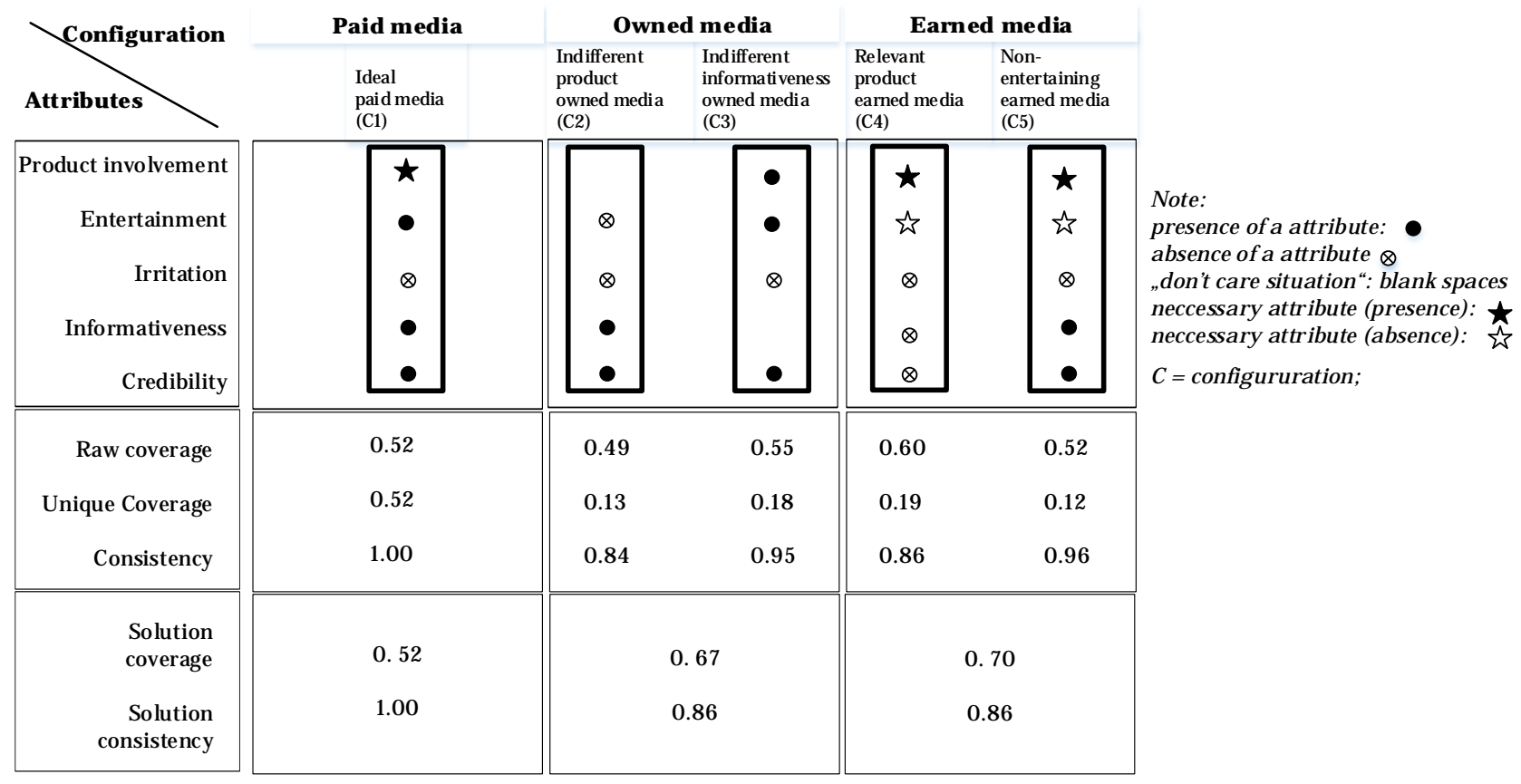

Figure 1. Graphical Representation of the Solution 
product involvement, and perceives the owned media as entertaining, non-irritating, but credible. In this configuration informativeness plays a subordinated role as informativeness can either be present or absent, we therefore label this configuration the indifferent informativeness owned media.

Results for earned media. The analysis for necessary attributes revealed two necessary attributes: product involvement (consistency $>0.92$, coverage $>$ 0.57 ) and non-entertainment (consistency $>0.92$, coverage $>0.59$ ). This means that to evoke a positive brand attitude through earned media, the consumer at least needs to have a high product involvement and needs to perceive the owned media as non-entertaining.

To understand what configurations lead to a positive brand attitude for earned media, the analysis reveals two configurations of sufficient attributes (see Figure 1 configurations C4 and C5). These configurations show that for earned media two ways exist, which lead to a positive brand attitude. The overall solution consistency is 0.86 and the coverage is 0.70. First, C4 shows that an earned media leads to a positive brand attitude when the consumer has a high product involvement, perceives the earned media as non-entertaining, non-irritating, non-informative and non-credible. We therefore label this configuration the relevant product earned media. The configuration C5 shows the second way how an earned media can lead to a positive brand attitude. Consumers need to have a high product involvement, need to perceive the earned media as non-entertaining and non-irritating, but as informative and credible. We therefore label this configuration the non-entertaining earned media.

Figure 1 furthermore shows the raw coverage which expresses the extent to which the configuration covers the cases leading to a positive brand attitude [43]. Additionally, the unique coverage is displayed in Figure 1 which refers to the unique contribution of the configuration excluding the contribution of other configurations [43] and the consistency of each configuration is displayed. Next, we will discuss the theoretical and practical implications of the results.

\section{Discussion}

Companies spend millions of dollars on social media marketing using paid, owned and earned media with the aim to create a positive brand attitude for consumers [1, 33, 47]. A positive brand attitude leads to consumers' commitment to the company, which increases companies' profit and thus has a high practical relevance for organizations [2, 52, 53]. Despite the existence of the three distinct types of media, companies do not know how they need to leverage the three types of media to evoke a positive brand attitude when consumers are exposed to the media. However, such knowledge is important as we know that individuals behave differently, while surfing online and being confronted with ads [13]. To create a better understanding of how companies can use paid, owned and earned media to create a positive brand attitude, this research bases on the foundation of the advertising value model (AVM) and takes a configurational approach using fsQCA [43]. With this approach, we meet the requirements of studying the asymmetric relationships [23, 40] between those attributes and reveal distinct configurations of sufficient attributes, which lead to a positive brand attitude.

So far, research has used the AVM with its attributes for all three types of media in the same way and thereby neglects that those three types of media differ and that individuals perceive these types of media differently. Thereby, the specific understanding of how each type of media influences consumers is limited. Furthermore, previous research considers all five attributes as equally important, which limits the practical application. In contradiction to that, we reveal different configurations of sufficient attributes for each type of media, where some attributes are necessary and therefore, more important than others to build a positive brand attitude. In more detail, for paid media we reveal one configuration of sufficient attributes (the ideal paid media). This configuration of sufficient attributes perfectly represents previous findings of research focusing on paid media [5, 10, 12, 25]. However, we extend this knowledge by identifying product involvement as a necessary attribute. This means that paid media only leads to a positive brand attitude if the product is relevant and important for the consumer. In contrast, the analysis for necessary attributes for owned media did not reveal any attributes. Yet we found that in contrast to paid media, two configurations of sufficient attributes for owned media lead to a positive brand attitude. The configuration indifferent informativeness owned media is similar to the configuration the ideal paid media yet the owned media does not need to be informative to lead to a positive brand attitude. The configuration indifferent product owned media reveals that owned media lead to a positive brand attitude even if the consumer does not have a product involvement. This means that owned media is the only media which can be used to promote products, which are not relevant and important to the consumer, yet yielding a positive brand attitude. An explanation for this would be that for owned media consumers freely decide to follow the brand and get information through owned media. The two configurations for earned media, namely relevant product earned media and non-entertaining earned media, differs from paid and owned media as well. We found that necessary attributes of earned media are 
product involvement and non-entertaining. This means that for earned media it is important that the media is not aimed at entertaining the consumer and the product advertised needs to be relevant for the consumer to evoke a positive brand attitude. Earned media furthermore varies, as the configuration relevant product earned media is the only configuration of sufficient attributes, which states that the media does not need to be credible or informative. This could mean that the consumer fully relies on the opinion of the influencer, who posts the earned media, and the consumer develops a positive brand attitude even if the media is not entertaining or informative, just because the media is posted by an influencer. In summary, the analysis revealed different configurations of sufficient attributes and different necessary attributes for each type of media. With this knowledge, we contribute that different research models need to be used depending on the type of media. The AVM in its original form is only appropriate for paid media, while we show that earned and owned media require different research models. Furthermore, we contribute by showing that not all attributes are equally important but that necessary conditions are needed to evoke a positive brand attitude.

With taking a configurational approach, we furthermore contribute in two ways. First, we reveal that not a single attribute of a media leads to a positive brand attitude but a configuration of sufficient attributes, which work together lead to a positive brand attitude (referred as causal conjunction). We furthermore, prove that the presence as well as the absence of attributes is connected to consumer's positive brand attitude. For instance, media, which is perceived as entertaining as well as media, which is not perceived as entertaining, can lead to a positive brand attitude (referred as asymmetry of the attributes). We thereby follow recent calls to better understand and consider asymmetric relationships of attributes and non-linear effects of influencing factors [40]. Furthermore, the results for paid media only revealed one configuration of sufficient attributes, which perfectly reflects previous findings [5, 10, 12, 25]. This means that the AVM with its five attributes is well suited to study the effect of paid media. In contrast, the results for owned media revealed two configurations each. This means for owned and earned media there is not one way but two ways how each media can create a positive brand attitude (referred as equifinality). This create a certain flexibility, as companies can achieve their goal of creating a positive brand attitude through different paths.

Second, with our results we also contribute by creating a typology of media, which results in a positive brand attitude. We provide a typology of five different media which differ in their attributes but all lead to a positive brand attitude. Typologies are a meaningful way of theorizing about complex phenomena and provide insights for practice and theory simultaneously $[11,14]$. With our typology of different paid, owned and earned media, we lay the foundation for further studies using multiple models. For instance, future research may design and test the revealed typology. As the results do not show any necessary attributes for owned media, future research may take a more explorative approach to identify further specific attributes for owned media. The same applies for earned media, meaning that future research may also focus on identifying specific attributes for earned media.

Furthermore, this typology of paid, owned and earned media provides useful implications for practice, which is outlined next. The typology of paid, owned and earned media. In general, companies should design non-irritating media. Furthermore, the typology suggests that a company, which uses paid media, should design ads matching the ideal paid media. This means for paid media, companies should design entertaining, non-irritating, informative and credible ads and try to deliver the paid media to a target group, who cares about the advertised product. When companies use owned media, our typology suggest two types of owned media. Companies do not need to care about their target group, as long as the owned media is informative and credible. When companies create owned media, which is not informative, the typology suggest delivering the owned media only to individuals, who have a high product involvement. Finally, companies need to manage earned media differently, as earned media creates a positive brand attitude through reaching consumers with a high product involvement. Additionally, the typology suggests that earned media does not need to be entertaining, but rather informative and credible.

\section{Conclusion}

Companies need to manage paid, owned and earned media to generate a positive brand attitude. This research reveals five types of the media which can be used by companies to generate a positive brand attitude.

\section{References}

[1] 440marketinggroup.com, "Social Ad Spend Surpasses Television: New Research » 440", 2018.

[2] Aaker, D.A. and R. Jacobson, "The value relevance of brand attitude in high-technology markets", Journal of Marketing Research (JMR), 38(4), 2001, pp. 485-493.

[3] Alves, H., C. Fernandes, and M. Raposo, "Social media marketing: A literature review and implications", Psychology \& Marketing, 33(12), 2016, pp. 1029-1038. 
[4] Bernerth, J.B. and H. Aguinis, "A critical review and best-practice recommendations for control variable usage", Personnel Psychology, 69(1), 2016, pp. 229-283.

[5] Brackett, L.K. and B.N. Carr, "Cyberspace Advertising vs. Other Media: Consumer vs. Mature Student Attitudes", Journal of Advertising Research, 41(5), 2001, pp. 23-32.

[6] Carmines, E.G. and R.A. Zeller, Reliability and validity assessment, Sage Publ., Newbury Park, Calif., 2008.

[7] Che, J.W.S., C.M.K. Cheung, and D.R. Thadani, "Consumer Purchase Decision in Instagram Stores:The Role of Consumer Trust", Hawaii International Conference on System Sciences 2017 (HICSS-50), 2017.

[8] Cheng, J.M.-S., C. Blankson, E.S.-T. Wang, and L.S.-L. Chen, "Consumer attitudes and interactive digital advertising", International Journal of Advertising, 28(3), 2009, pp. 501-525.

[9] Chin, W.W., J.B. Thatcher, and R.T. Wright, "Assessing common method bias: Problems with the ULMC technique", MIS Quarterly, 2012, pp. 1003-1019.

[10] Dao, V.-T.W., A. Nhat Hanh Le, J. Ming-Sung Cheng, and D. Chao Chen, "Social media advertising value: The case of transitional economies in Southeast Asia", International Journal of Advertising, 33(2), 2014, pp. 271294.

[11] Delbridge, R. and P.C. Fiss, "Editors' comments: styles of theorizing and the social organization of knowledge", Academy of management review, 38(3), 2013, pp. 325331.

[12] Ducoffe, R.H., "Advertising Value and Advertising the Web", Journal of Advertising Research, 36(5), 1996, pp. 21-35.

[13] Eckhardt, A., C. Maier, J.J. Hsieh, T. Chuk, A.B. Chan, J.H. Hsiao, and R. Buettner, "Objective measures of IS usage behavior under conditions of experience and pressure using eye fixation data", 2013.

[14] Fiss, P.C., "Building better causal theories: A fuzzy set approach to typologies in organization research", Academy of Management Journal, 54(2), 2011, pp. 393-420.

[15] Fornell, C. and D.F. Larcker, "Evaluating structural equation models with unobservable variables and measurement error", Journal of Marketing Research, 18(1), 1981, pp. 39-50.

[16] Füller, J., H. Mühlbacher, K. Matzler, and G. Jawecki, "Consumer empowerment through internet-based cocreation", Journal of Management Information Systems, 26(3), 2009, pp. 71-102.

[17] Goh, K.-Y. and W.J. Ping, "Engaging Consumers with Advergames: An Experimental Evaluation of Interactivity, Fit and Expectancy", Journal of the Association for Information Systems, 15(7), 2014, pp. 388-421.

[18] Henseler, J., C.M. Ringle, and M. Sarstedt, "A new criterion for assessing discriminant validity in variancebased structural equation modeling", Journal of the Academy of Marketing Science(43:1), 2014.

[19] Hulland, J.S., "Use of partial least squares (PLS) in strategic management research: A review of four recent studies", Strategic Management Journal, 20(2), 1999, pp. 195-204.

[20] Kim, J.U., W.J. Kim, and S.C. Park, "Consumer perceptions on web advertisements and motivation factors to purchase in the online shopping", Computers in Human Behavior, 26(5), 2010, pp. 1208-1222.

[21] Lawrence, B., S. Fournier, and F. Brunel, "When companies don't make the ad: A multimethod inquiry into the differential effectiveness of consumer-generated advertising", Journal of Advertising, 42(4), 2013, pp. 292 307.

[22] Lin, F.-H. and Y.-F. Hung, "The value of and attitude toward sponsored links for internet information searchers", Journal of Electronic Commerce Research, 10(4), 2009, p. 235.

[23] Liu, Y., J. Mezei, V. Kostakos, and H. Li, "Applying configurational analysis to IS behavioural research: A methodological alternative for modelling combinatorial complexities", Information Systems Journal, 27(1), 2017, pp. 59-89.

[24] Lovett, M.J. and R. Staelin, "The Role of Paid, Earned, and Owned Media in Building Entertainment Brands: Reminding, Informing, and Enhancing Enjoyment", Marketing Science, 35(1), 2016, pp. 142-157.

[25] MacKenzie, S.B. and R.J. Lutz, "An Empirical Examination of the Structural Antecedents of Attitude toward the Ad in an Advertising Pretesting Context", Journal of Marketing, 53(2), 1989, p. 48.

[26] Marx, A., "Towards more robust model specification in QCA results from a methodological experiment", American Sociological Association, Philadelphia, PA, 2006, 2006.

[27] Mattke, J., C. Maier, L. Müller, and T. Weitzel, "Bitcoin Resistance Behavior: A QCA Study Explaining Why Individuals Resist Bitcoin as a Means of Payment", ICIS 2018 Proceedings, San Francisco, CA, 2018.

[28] Mattke, J., L. Müller, and C. Maier, "Why Do Individuals Avoid Social Media Advertising: A Qualitative Comparison Analysis Study", ECIS 2018 Proceedings (Portsmouth, UK), 2018.

[29] Mattke, J., L. Müller, C. Maier, and H. Graser, "Avoidance of Social Media Advertising", in Proceedings of the 2018 ACM SIGMIS Conference on Computers and People Research - SIGMIS-CPR'18, R. Kishore, D.

Beimborn, R.K. Bandi, B. Aubert, D. Compeau, and M. Tarafdar, Editors, the 2018 ACM SIGMIS Conference, Buffalo-Niagara Falls, NY, USA. 2018. ACM Press: New York, New York, USA.

[30] Misangyi, V.F., T. Greckhamer, S. Furnari, P.C. Fiss, D. Crilly, and R. Aguilera, "Embracing causal complexity: The emergence of a neo-configurational perspective", Journal of management, 43(1), 2017, pp. 255-282.

[31] Müller, L., J. Mattke, and C. Maier, "\# Sponsored\# Ad: Exploring the Effect of Influencer Marketing on Purchase Intention", AMCIS 2018 Proceedings, New Orleans, USA, 2018.

[32] Müller, L., J. Mattke, C. Maier, and T. Weitzel, "The Curse of Mobile Marketing: A Mixed Methods Study on Individuals’ Switch to Mobile Ad Blockers", ICIS 2017 Proceedings, Seoul, South Korea, 2017.

[33] Osman, M., "28 Powerful Facebook Stats Your Brand Can’t Ignore in 2018", 2018.

[34] Pappas, I.O., "User experience in personalized online shopping: A fuzzy-set analysis", European Journal of Marketing, 52(7/8), 2018, pp. 1679-1703. 
[35] Pavlou, P., H. Liang, and Y. Xue, "Understanding and mitigating uncertainty in online exchange relationships: A principle-agent perspective", MIS Quarterly, 31(1), 2007, pp. 105-136.

[36] Perkins, A.W. and M.R. Forehand, "Implicit SelfReferencing: The Effect of Nonvolitional Self-Association on Brand and Product Attitude", Journal of Consumer Research, 39(1), 2012, pp. 142-156.

[37] Petty, R.E. and J.T. Cacioppo, "Issue involvement can increase or decrease persuasion by enhancing messagerelevant cognitive responses", Journal of personality and social psychology, 37(10), 1979, p. 1915.

[38] Petty, R.E., J.T. Cacioppo, and D. Schumann, "Central and peripheral routes to advertising effectiveness: The moderating role of involvement", Journal of Consumer Research, 10(2), 1983, pp. 135-146.

[39] Podsakoff, P.M., S.B. MacKenzie, J.-Y. Lee, and N.P. Podsakoff, "Common method biases in behavioral research: A critical review of the literature and recommended remedies", Journal of Applied Psychology, 88(5), 2003, p. 879.

[40] Polites, G.L., E. Karahanna, and L. Seligman, "Intention-behaviour misalignment at B2C websites: When the horse brings itself to water, will it drink?", European Journal of Information Systems, 27(1), 2017, pp. 22-45.

[41] R. Sinkovics, R.-J.“B.”J.R., J. Henseler, C.M. Ringle, and M. Sarstedt, "Testing measurement invariance of composites using partial least squares", International Marketing Review, 33(3), 2016, pp. 405-431.

[42] Ragin, C.C., "User's Guide to Fuzzy-Set/Qualitative Comparative Analysis 2.0", Department of Sociology, University of Arizona., Tucson, Arizona, 2006.

[43] Ragin, C.C., Redesigning social inquiry: Fuzzy sets and beyond, Wiley Online Library, 2009.

[44] Schneider, C.Q. and C. Wagemann, "Standards of good practice in qualitative comparative analysis (QCA) and fuzzy-sets", Comparative Sociology, 9(3), 2010, pp. 397418.

[45] Stephen, A.T. and J. Galak, "The effects of traditional and social earned media on sales: A study of a microlending marketplace", Journal of Marketing Research (JMR), 49(5), 2012, pp. 624-639.

[46] Taylor, D.G., J.E. Lewin, and D. Strutton, "Friends, fans, and followers: Do ads work on social networks?: how gender and age shape receptivity", Journal of Advertising Research, 51(1), 2011, pp. 258-275.

[47] https://influencermarketinghub.com/the-rise-ofinfluencer-marketing/, accessed 2-28-2018.

[48] Thompson, D.V. and P. Malaviya, "Consumer-generated ads: Does awareness of advertising co-creation help or hurt persuasion?", Journal of Marketing, 77(3), 2013, pp. 3347.

[49] Tucker, C.E., "Social Networks, Personalized Advertising, and Privacy Controls", Journal of Marketing Research (JMR), 51(5), 2014, pp. 546-562.

[50] https://www.emarketer.com/Report/US-Social-Trends2017-eMarketers-Predictions-Attribution-Live-StreamingMessaging-Influencer-Marketing-More/2001920, accessed 6-11-2018.

[51] Veirman, M. de, V. Cauberghe, and L. Hudders, "Marketing through Instagram influencers: The impact of number of followers and product divergence on brand attitude", International Journal of Advertising, 36(5), 2017, pp. 798-828.

[52] Xie, K. and Y.-J. Lee, "Social media and brand purchase: Quantifying the effects of exposures to earned and owned social media activities in a two-stage decision making model", Journal of Management Information Systems, 32(2), 2015, pp. 204-238.

[53] Zhang, J. and E. Mao, "From Online Motivations to Ad Clicks and to Behavioral Intentions: An Empirical Study of Consumer Response to Social Media Advertising", Psychology \& Marketing, 33(3), 2016, pp. 155-164.

[54] Zhang, P., "What consumers think, feel, and do toward digital ads: a multi-phase study", ECIS 2011 Proceedings, Helsinki, Finland, 2011.

[55] Zheng, X., C.M.K. Cheung, M.K.O. Lee, and L. Liang, "Building brand loyalty through user engagement in online brand communities in social networking sites", Information Technology \& People, 28(1), 2015, pp. 90106. 